\title{
PUSAT KREATIVITAS REMAJA DAN ANAK MUDA MILENIAL
}

\author{
Stefanus Sutanto"), Dewi Ratnaningrum ${ }^{2)}$ \\ 1) Program Studi S1 Arsitektur, Fakultas Teknik, Universitas Tarumanagara, stefanussutta@gmail.com; \\ 2) Program Studi S1 Arsitektur, Fakultas Teknik, Universitas Tarumanagara, dewir@ft.untar.ac.id
}

\begin{abstract}
Abstrak
Pada zaman modern ini kita sering mendengar istilah Milenial, Milenial adalah anak muda pada sekarang ini yang lahir di antara tahun 1980-2000an. Terutama di Indonesia pun kaum Milenial sangatlah banyak, kaum milenial pun adalah kaum muda yang pastinya memiliki banyak kemampuan dan kreativitas yang beragam yang tentunya dapat di kembangkan dalam hal yang positif untuk kemampun dalam diri mereka masing-masing. Kegiatan yang dapat membangun kreativitas mereka tentunya sangat menyenangkan selain dapat mengisi waktu dengan hal yang berguna selain itu pun juga bisa menambah kemampuan diri untuk masa depan agar bisa memiliki jiwa entrepreneur. Proyek ini memiliki tujuan untuk mewadahi para kaum milenial bisa mengembangkan kemampuan mereka serta kreativitas yang mereka miliki untuk di kembangkan untuk kedepannya agar bisa mempunyai jiwa entrepreneur selain itu juga dapat mengisi waktu dengan hal yang berguna dan positif serta bersosialiasi bertemu dengan orang banyak yang memiliki kegemaran dan kreativitas yang sama sehingga dapat menambah wawasan. Proyek ini adalah tempat yang mewadahi para remaja dan anak muda milenial untuk mengembangkan bakat dan kreativitas mereka dalam kegiatan yang mereka gemari. sekaligus menjadi tempat pengajaran non formal baru bagi kota Tangerang khusus nya Alam Sutera. Metode yang digunakan adalah deksriptif di mana dilakukan pengamatan langsung di lapangan dan analisis data - data untuk menentukan kebutuhan ruang hingga didapatkan hubungan ruang serta sirkulasi di dalam tapak. Dari hasil yang sudah di dapati, terbentuklah bentuk massa bangunan yang bundar/melengkung, dengan façade yang cenderung modern, Menggambarkan anak muda yang dinamis dan tidak terpaku dalam kegiatan yang monotone saja. Kelompok kegiatan dibuat berdasarkan zoning dan memperhatikan privasi dari tiap kegiatan serta setiap kegiatan di dapat dari hasil survey dengan sebagian besar anak muda dan remaja yang tinggal di kawasan Alam Sutera.
\end{abstract}

Kata kunci: Alam Sutera; kreativitas; milenial; pendidikan; pusat

\begin{abstract}
In this modern age we often hear the term Millennial, Millennial is a young person today who was born between 1980-2000an. Especially in Indonesia even Millennials are very numerous, millennials are young people who certainly have many abilities and diverse creativity which of course can be developed in a positive way for the ability in each of them. Activities that can build their creativity are certainly very pleasant besides being able to fill their time with useful things besides that they can also increase their ability for the future so they can have an entrepreneurial spirit. This project aims to accommodate millennials who can develop their abilities and the creativity they have to develop in the future so that they can have an entrepreneurial spirit besides being able to fill time with useful and positive things and socializing to meet many people who have a passion and the same creativity so that it can add insight. This project is a place that accommodates teenagers and millennial young people to develop their talents and creativity in the activities they enjoy. as well as being a new non-formal teaching place for the Tangerang city, specifically Alam Sutera. The method used is descriptive where direct observation is carried out in the field and analysis of data - data to determine the space requirements to obtain the relationship of space and circulation in the site. From the results that have been found, a round / curved form of building mass is formed, with a façade that tends to be modern, depicting young people who are dynamic and not fixated in monotone activities. Activity groups are based on zoning and pay attention to the privacy of each activity and each activity can be obtained from the results of a survey with most young people and adolescents living in the Alam Sutera area.
\end{abstract}

Keywords: Alam Sutera; center; creativity; education; millennials 


\section{PENDAhULUAN}

\section{Latar Belakang}

Pada dewasa ini kita sering mendengar kata Milenials / Kaum Milenials. Milenials itu sedniri adalah seseorang yang terlahir dari tahun 1980-2000an, Generasi itu juga disebut Generasi Praktis, karena untuk mendapatkan informasi hanya dengan mengakses internet (sumber: Wikipedia). Generasi muda dengan segudang potensi yang dimiliki, sudah saatnya untuk menjadi pionir atau penggerak perkembangan medsos. Generasi muda / generasi Milenials yang merupakan penghuni dari internet atau hidup di zaman internet, sudah sepantasnya bukan hanya menjadi pengguna yang pasif. Bukan hanya sekadar melihat. Mereka harus menjadi pengguna yang berpartisipasi aktif sebagai pembuat konten blog, pemberi kritik dan saran pada forum online. Banyak sekali hal-hal yang dapat dilakukan oleh generasi muda sebagai partisipasi aktif dalam media sosial. Sebagai contoh generasi muda dapat membuat blognya / konten nya tentang kegemaran nya maupun tentang kreatifitas nya sendiri dimana di dalamnya ditulis pengalaman pribadi, hobi atau kegemaran, baik di bidang seni, olahraga, bisnis, traveling dll. Sehingga bisa menjadi contoh untuk orang lainnya dan juga bisa menjadi dampak positif yang berguna untuk orang lain yang melihantnya. Dengan seluruh kejadian yang di alami oleh kaum milenials sekarang ini di ininkan mendirikan bangunan arsitektur yang bisa membantu mereka yang mempunyai suatu bakat dan kreatifitas untuk lebih di kembangkan lagi di bangunan ini yang mempunyai tipe fungsi bangunan seperti workshop, kursus, pengajaran, bersosialisai, komunitas dengan sesama yang memiliki kegemaran, bakat serta kreatifitas yang sama. Akan mendirikan bangunan seperti pusat kreatifitas dengan sistem seperti workshop pelatihan dengan berbagai macam aspek untuk para remaja milenials agar bisa menjadi seorang enterepreneur dan bisa memanfaatkan sosial media, internet dan smartphone untuk mengembangkan bakat serta kreatifitas seperti misalnya gemar seni, berbisnis, fashion, makeup, memasak, vlogging, bercerita, komedi atau lainnya bisa bertemu dengan komunitas yang memiliki kegemaran yang sama. Serta terdapat para pengajar / bintang tamu yang berkompeten di bidangnya untuk mengajari serta bertukar pikiran dengan remaja milenials tentunya yang berhubungan dengan bakat, kegemarannya. Dengan di dirikan bangunan seperti ini diharapkan remaja milenial bisa mempunyai bekal kemampuan, lebih berani, percaya diri dan mampu bersaing di dunia luar.

\section{METODE}

Menurut data.tangerang.go.id, kawasan baru Alam Sutera adalah salah satu kawasan di area Tangerang yang unggulan serta mempunyai daya tarik dari penduduk kota lain sekitarnya seperti kota Jakarta. Dan dengan berbagai pilihan program wisata seperti wisata belanja dan kuliner, daerah Alam Sutera bisa dikembangkan lebih lagi untuk menjadi wisata publik yang memiliki potensi menarik pengunjung untuk bangunan pusat kreativitas baik dari kawasan Alam Sutera maupun luar kawasan tersebut (Gambar 1).

Setelah menentukan area yang memiliki banyak kaum milenial sebagai lokasi yang dipilih yaitu lebih tepatnya di daerah Alam Sutera, daerah tersebut di ambil karena berpotensi dikembangkan menjadi daerah yang bisa sebagai pusat kreativitas remaja dan anak muda milenial karena kawasan Alam Sutera adalah kawasan di Tangerang yang terdapat banyak sekali kaum milenial baik tinggal disana maupun sekolah dan berkuliah di kawasan Alam Sutera (Gambar 2). 


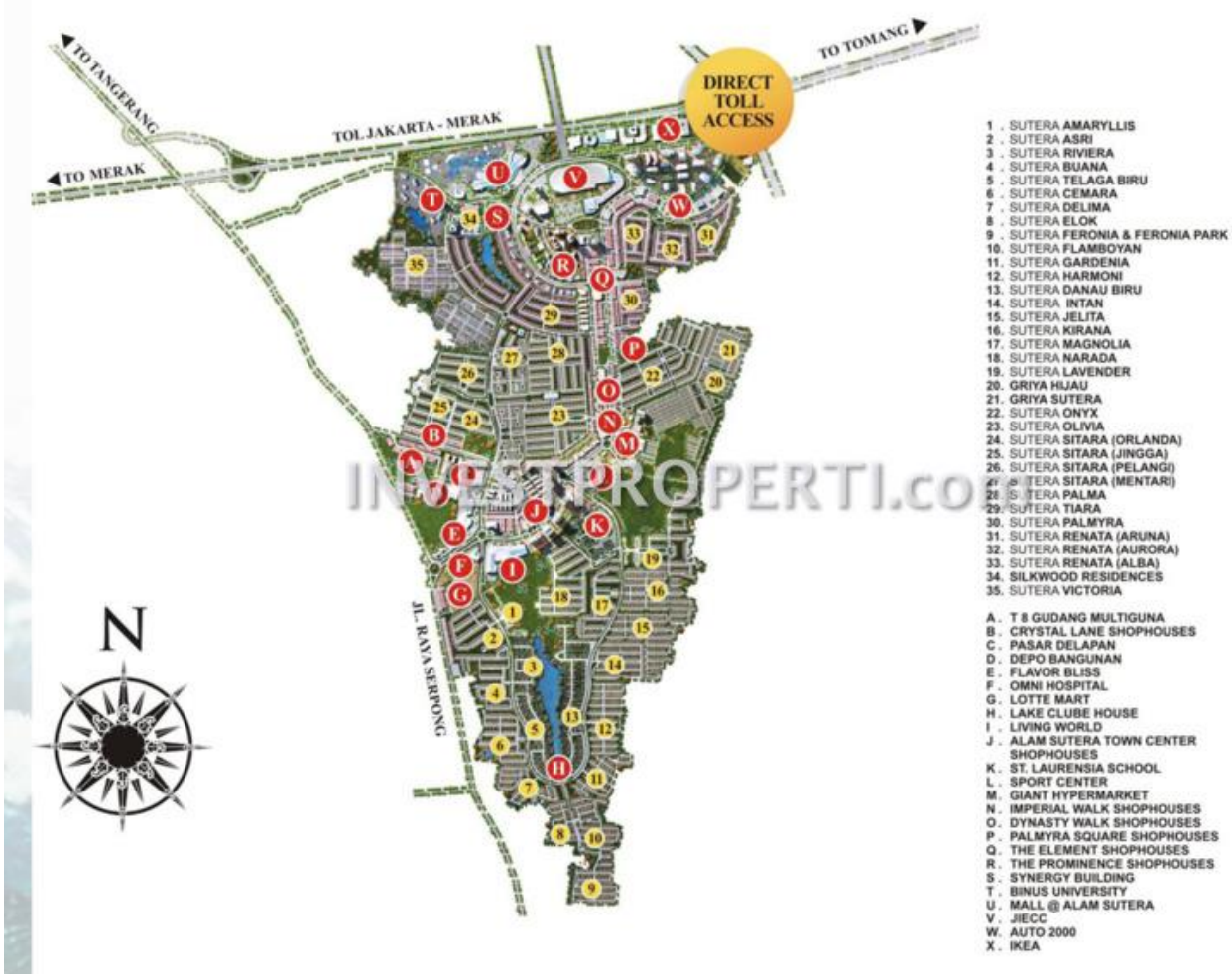

Gambar 1. Kawasan Alam Sutera terdapat banyak permukiman untuk milenials serta sarana dan prasarana kawasan tersebut

Sumber: http://investproperti.com/baru/alam-sutera/

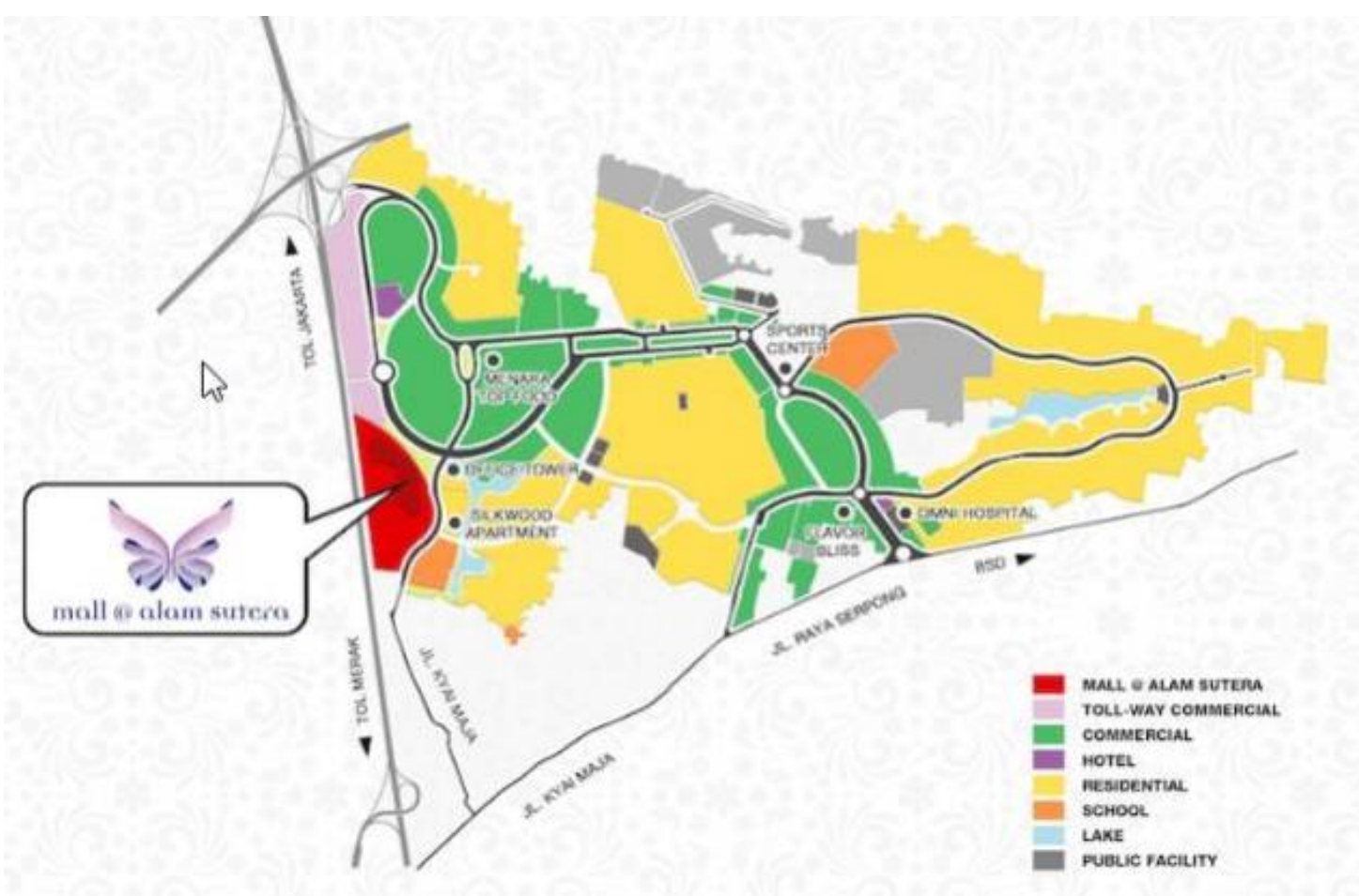

Gambar 2. Peta Zonasi Kecamatan Pakulonan Sumber: http://alamsuterarealty.co.id/ 
Setelah menentukan Kecamatan Pakulonan yaitu daerah kawasan sisi utara Alam Sutera sebagai kawasan terpilih, dianalisa lagi dengaan radius lebih kecil untuk menentukan tapak terpilih.

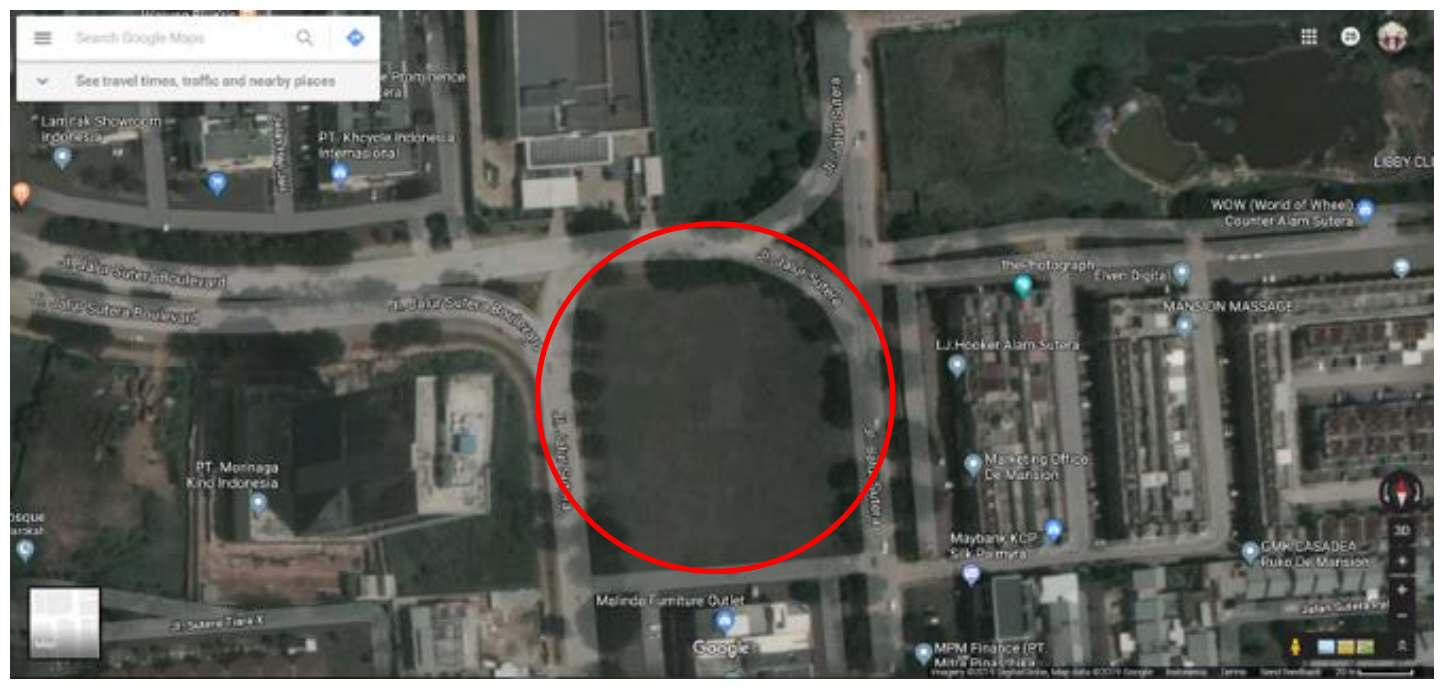

Gambar 3 . Analisa Daerah sekitar tapak di Alam Sutera Sumber : google maps yang diolah kembali

Tapak terletak di dekat jalan tol Jakarta - Tangerang. Tapak berada di zona perdagangan dan terletak di pusat kawasan Alam Sutera. Dari segi lokasi sekitar tapak yang di pilih, sekitar tapak terdapat banyak hunian cluster, ruko 3-4 lantai, pusat perbelanjaan, kantor, sekolah dan universitas ternama. Lokasi tapak berada di tengah sebagai pusat dari lokasi sarana dan prasarana tersebut, sehingga di harapkan banyak pengunjung milenial yang bisa ke bangunan proyek pusat kreativitas tersebut. Tapak tersebut sangatah tepat karena di kelilingi oleh 3 jalan besar, terdapatnya TOD di depan tapak tersebut dan juga memiliki luasan yang cukup untuk membangun proyek pusat kreativitas remaja dan anak muda milenial. Luas tapak $6.300 \mathrm{~m} 2, \mathrm{KDB}$ $70 \%$, KB 5 (max 20m), GSB 3, KDH 30\%, dan Basement 70\%.

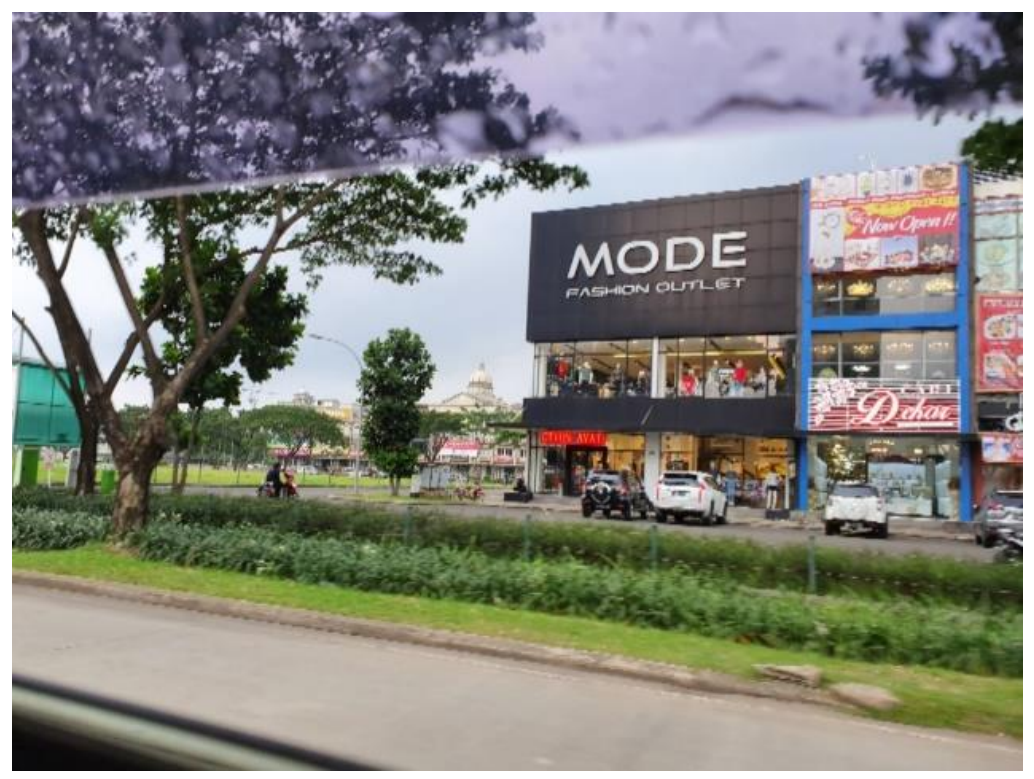

Gambar 4. Kondisi Sekitar Tapak

Sumber : dokumentasi pribadi 


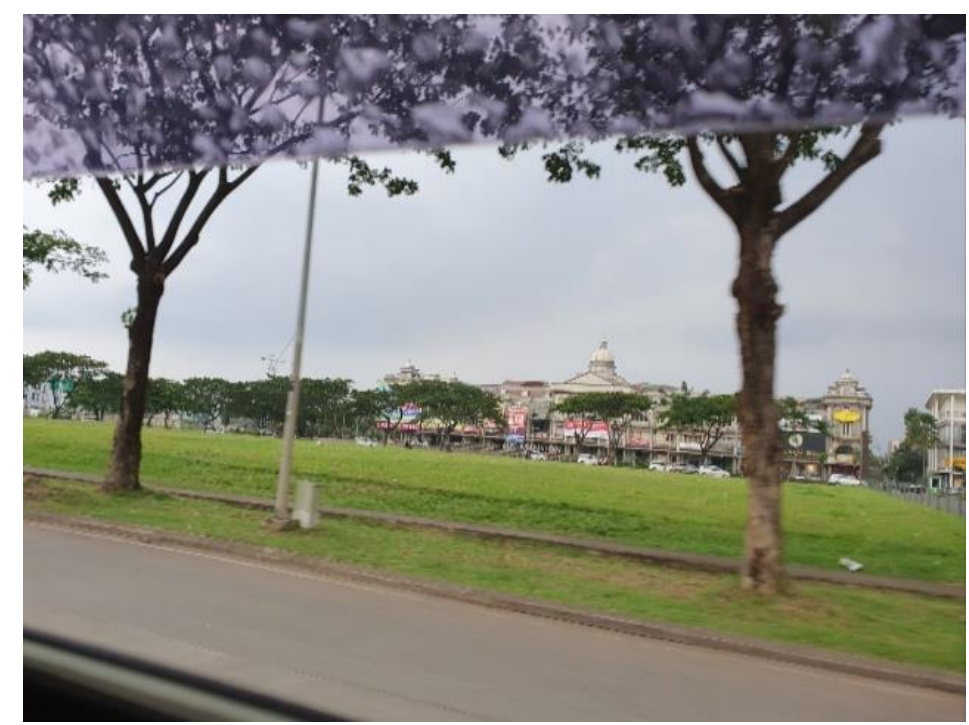

Gambar 5. Kondisi Tapak

Sumber : dokumentasi pribadi

Zonasi tapak akan terbagi menjadi publik, semi privat dan privat. Zona publik yaitu ruang outdoor area, restoran dan beberapa gerai lainnya. Konsep perencanaan tapak meliputi penanganan permasalahan tapak dan zoning kegiatan dan pengguna ruang. Akses masuk utama akan berpusat pada bagian sisi Timur tapak dan akses keluar pada bagian Barat tapak. Zoning untuk ruang ditentukan oleh faktor pencahayaan sinar matahari, privasi, kebisingan, kegiatan dan kebutuhan sesama ruang. Maka itu, zoning area belajar akan masing-masing berdekatan dan terletak lebih dalam dari jalanan utama. Zoning untuk area bermain terletak ditengah akan memberi sirkulasi angin dan pencahayaan dan memudahkan akses bagi anak-anak dan remaja. Zoning untuk area publik, servis dan kantor akan terletak lebih dekat dari jalan sebab untuk mudah di akses $\&$ sebagai pengahalang kebisingan serta privasi bagi area belajar.

\section{DISKUSI DAN HASIL}

Program yang diusulkan adalah Pusat kreativitas Remaja dan Anak Muda Milenial, yang memiliki tujuan untuk mengembangkan potensi para milenial di kawasan Alam Sutera dan sekitarnya untuk bisa mendapatkan Pendidikan non formal yang bersifat kelas dan workshop sesuai minat bakat pengunjung, serta bisa bertemu dengan taman yang memiliki bakat yang sama sehingga dapat berbagi ilmu yang belum banyak diwadahi di Indonesia.

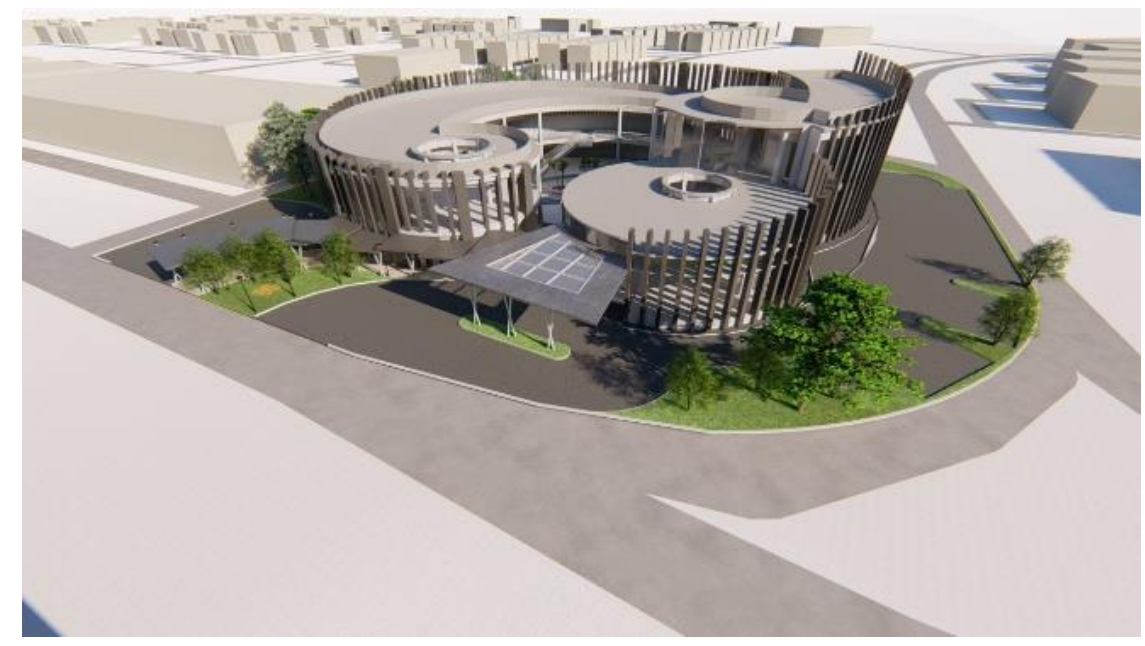

Gambar 6. Perspektif Eksterior 
Program ruang berasal dari hasil studi 3 preseden. Yaitu kombinasi dari fungsi utama dan fungsi pendukung. Konsep yang diusung adalah suatu tempat dimana warga Tangerang dan sekitarnya bisa melakukan kegiatan yang dapat mengembangkan minat bakat kreativitas sehingga di harpakan pengunjung bisa memiliki jiwa wirausaha / entrepreneur.

\section{HASIL}

Contoh pertanyaan dan hasil pembagian angket / koesioner yang di berikan kepada 40 responden secara acak :

$\begin{aligned} \begin{array}{r}\text { Pertanyaan pilihan (pilih satu) : } \\ \text { 1. Jenis Kelamin : }\end{array} & \text { *Kebanyakan berjenis kelamin } \\ \text { a. Laki-Laki (17) } & \text { perempuan. Tetapi memiliki selisih } \\ \text { b. Perempuan (23) } & \text { yang tidak terlalu signifikan } \\ \text { 2. Usia : } & \text { *Rata-rata berumur masih remaja anak } \\ \text { a. } 15-19(6) & \text { muda beranjak ke dewasa yaitu } \\ \text { b. } 20-24(14) & \text { berumur } 20-24 \text { tahun. Beranggapan } \\ \text { c. } 25-29(11) & \text { pusat pengembangan bakat dan } \\ \text { d. } 30-34(7) & \text { kreatifitas remaja \& anak muda sangat } \\ \text { e. }>34(2) & \text { di perlukan untuk masa dewasa } \\ & \text { mereka. } \\ \text { 3. Profesi : } & \text { *Kegiatan sehari-sehari yaitu sebagai } \\ \text { a. Pelajar (4) } & \text { Mahasiswa/i. beranggapan kegiatan } \\ \text { b. Mahasiswa/i (18) } & \text { mereka sehari-hari masih ke kampus } \\ \text { c. Pekerja (15) } & \text { saja. Perlu kegiatan lain seperti } \\ \text { d. Nganggur (3) } & \text { pengembangan kreatifitas dan bakat. } \\ & \text { Sehingga ketika sudah lulus sudah } \\ & \text { mempunyai gambaran pekerjaan, yang } \\ \text { 4. Status : } & \text { sesuai dengan minat bakat. } \\ \text { a. Belum menikah (29) } & \text { *Sebagian besar status masih belum } \\ \text { b. Menikah (11) } & \text { menikah. Sehingga beranggapan masih } \\ & \text { punya banyak waktu di luar rumah } \\ & \text { untuk mengikuti aktifitas seperti } \\ & \text { pengembangan bakat dan kreatifitas }\end{aligned}$

\begin{tabular}{|c|c|c|c|c|}
\hline NO & KETERANGAN & YA & $\begin{array}{l}\text { RAGU- } \\
\text { RAGU }\end{array}$ & TIDAK \\
\hline 1 & 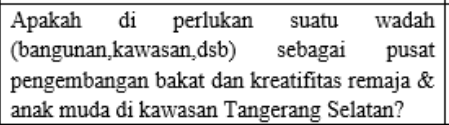 & 36 & 4 & - \\
\hline 2 & $\begin{array}{l}\text { Menurut saudara/i apakah sebuah bakat, minat } \\
\text { dan kreatifitas perlu di latih dan di } \\
\text { kembangkan untuk bekal kedepannya? }\end{array}$ & 40 & - & - \\
\hline 3 & $\begin{array}{l}\text { Apakah jika di dirikan bangunan sebagai pusat } \\
\text { pengembangan bakat dan kreatifitas remaja \& } \\
\text { anak muda di kawasan Tangerang Selatan } \\
\text { khususnya di Alam Sutera saudara/i sangat } \\
\text { minat untuk datang? }\end{array}$ & 32 & 8 & - \\
\hline 4 & $\begin{array}{l}\text { Jika bangunan sudah beroprasional, saudara } / \mathrm{i} \\
\text { akan mengajak teman / keluarga (remaja dan } \\
\text { anak muda dengan rentang umur } 15-28 \text { tahun) } \\
\text { untuk datang ke pusat pengembangan bakat } \\
\text { dan kreatifitas remaja \& anak muda, untuk } \\
\text { mengembangkan bakat, minat dan kreatifitas? }\end{array}$ & 35 & 5 & - \\
\hline 5 & $\begin{array}{l}\text { Jika bangunan sudah berjalan sekitar } 5 \text { tahun } \\
\text { dari di dirikannya, jika menurut saudara/i ilmu } \\
\text { yang di ajarkan sangatlah penting dan } \\
\text { saudara/i sudah memuka usaha sendiri dari } \\
\text { pengajaran yang selama ini di ikuti di } \\
\text { bangunan ini. Apakah saudara/i akan datang } \\
\text { lagi kebangunan ini untuk mengikuti kegiatan } \\
\text { (contoh:Workshop) lainnya? }\end{array}$ & 38 & 2 & - \\
\hline 6 & $\begin{array}{l}\text { Jika saudara/i sudah memiliki usaha sendiri } \\
\text { dengan ilmu yang di bekali dari tempat ini dan } \\
\text { sudah menjadi senior, apakah saudara/i } \\
\text { bersedia untuk menjadi pengajar/bintang tamu } \\
\text { untuk junior/pengunjung lainnya? }\end{array}$ & 33 & 7 & - \\
\hline
\end{tabular}

Tabel 1. Hasil Angket Survey 
Pertanyaan pilihan :

5. Pernahkah saudara/i mengikuti kegiatan pengembangan bakat dan kreatifitas tempat lain?
a. Pernah (23)
c. Ragu-ragu (3)
b. Tidak (14)

Kegiatan/tema apa yang saudara/i minati di pusat pengembangan bakat dan kreatifitas remaja \& anak muda? (boleh memilih lebih dari satu) :
a. Seni / art (24)
b. Bisnis (23)
c. Home \& Living (21)
d. Food \& Beverages / makanan minuman (25)
e. Fashion (22)
f. Travelling (19)
g. Tutor (8)

*seluruh kegiatan sangat banyak peminatnya, terutama $F \& B$ seluruh kegiatan di minati jika di buat menjadi kegiatan di bangunan ini.

6. Dalam melakukan kegiatan pengembangan bakat dan kreatifitas remaja \& anak muda. Saudara/i lebih tertarik dengan kegiatan seperti apa?
a. Seminar (6)
c. Kelas (9)
b. Workshop (26)
d. Ketiganya (2)

7. Dalam melakukan kegiatan pengembangan bakat dan kreatifitas remaja \& anak muda (workshop/kelas), berapakah menurut saudara/i yang pas jumlah orang/pengunjung lain dalam satu ruangan?
a. $10-15$ orang (12)
b. $16-20$ orang (11)
c. 21-25 orang (7)
d. 26-30 orang (6)
e. Tidak masalah, asal suasana nyaman dan kondusif (4)

8. Berapa lama (waktu) yang akan saudara/i ingin habiskan jika sedang melakukan kegiatan pengembangan bakat dan kreatifitas remaja \& anak muda?
a. 1-2 jam (3)
c. 4-6 jam (14)
b. 2-4 jam (17)
d. $>6$ jam (6)

9. Berapa sering (hari) yang akan saudara/i melakukan kunjungan di pusat pengembangan bakat dan kreatifitas remaja \& anak muda?
a. $1 \mathrm{kali} /$ minggu (9)
b. $2 \mathrm{kali} /$ minggu (11)
c. $3 \mathrm{kali} /$ minggu (6)
d. Setiap ada kegiatan yang menurut saya menarik, saya akan selalu datang (14)

\section{Tabel 2. Hasil Angket Survey}

Berdasarkan pengambilan data yang di lakukan dengan survey menyebar angket ke beberapa responden remaja dan anak muda dan wawancara secara langsung didapatkan 6 program program utama yang ingin diusulkan yaitu, makanan minuman / food \& beverages, seni / art, bisnis, fashion, home \& living, traveling. Jenis kegiatan seperti itulah yang di gemari oleh kaum milenial di kawasan Alam Sutera. Berdasarkan analisa dan hasil desain maka didapatkan luas lantai dasar $1.867 \mathrm{~m}^{2}$, lantai dua $1.580 \mathrm{~m}^{2}$. 


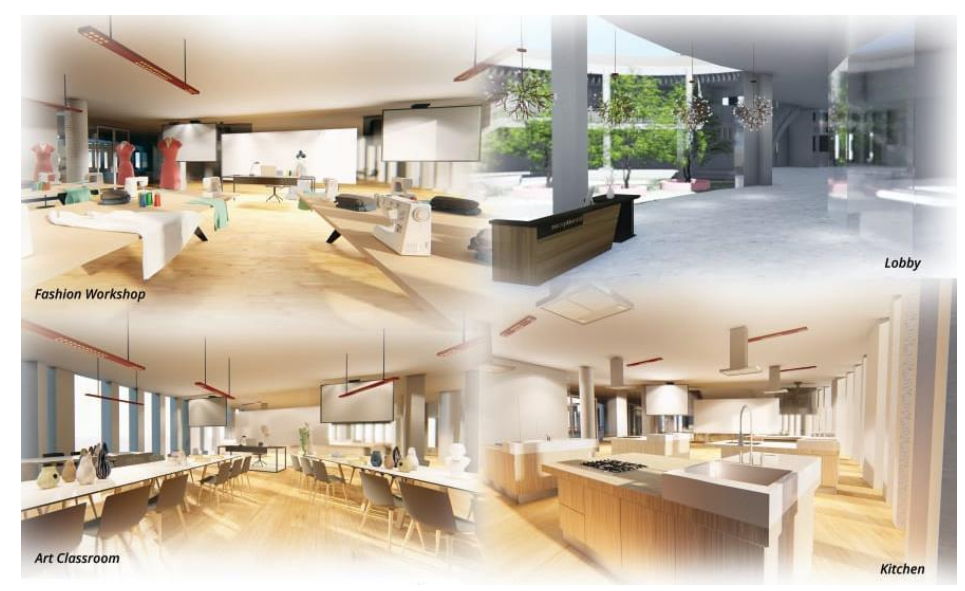

Gambar 8. Perspektif Ruang Dalam

Ruang dalam terdapat beberapa ruang kelas dan ruang workshop. Ruangan tersebut di buat se nyaman mungkin dan kekinian sehingga para pengunung milenial bisa merasakan kesan nyaman dan senang jika berada di dalam ruangan pendidikan non formal tersebut. Sehingga bisa mengikuti kegiatan pengembangan kreativitas minat bakat dengan senang.
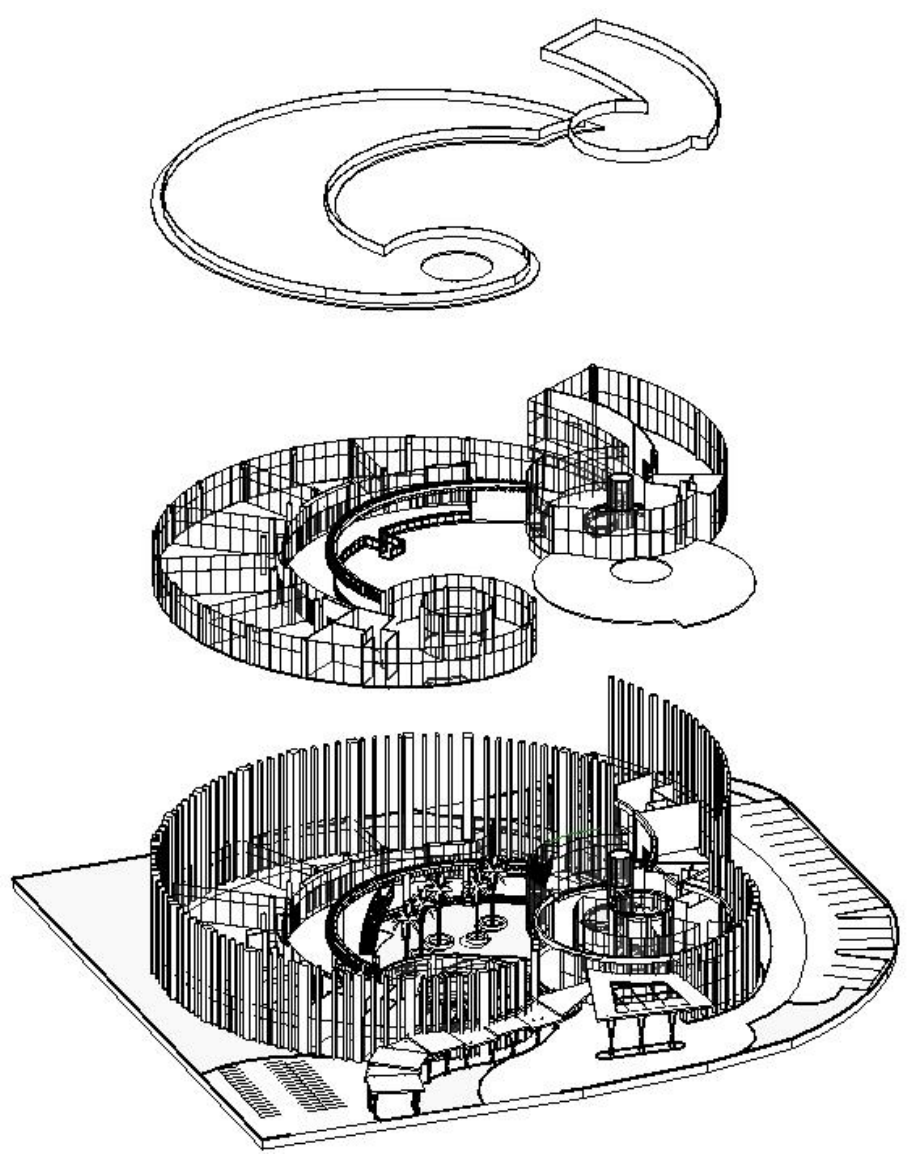

Gambar 9. Exploded Denah

Ruangan dan bentuk bangunan di buat se dinamis mungkin seperti sifat dasar milenial yaitu dinamis. Pembagian ruangan di buat dengan efisien dan memanfaatkan luasan dengan maksimal sehingga tidak ada ruang yang terbuang sia-sia. 

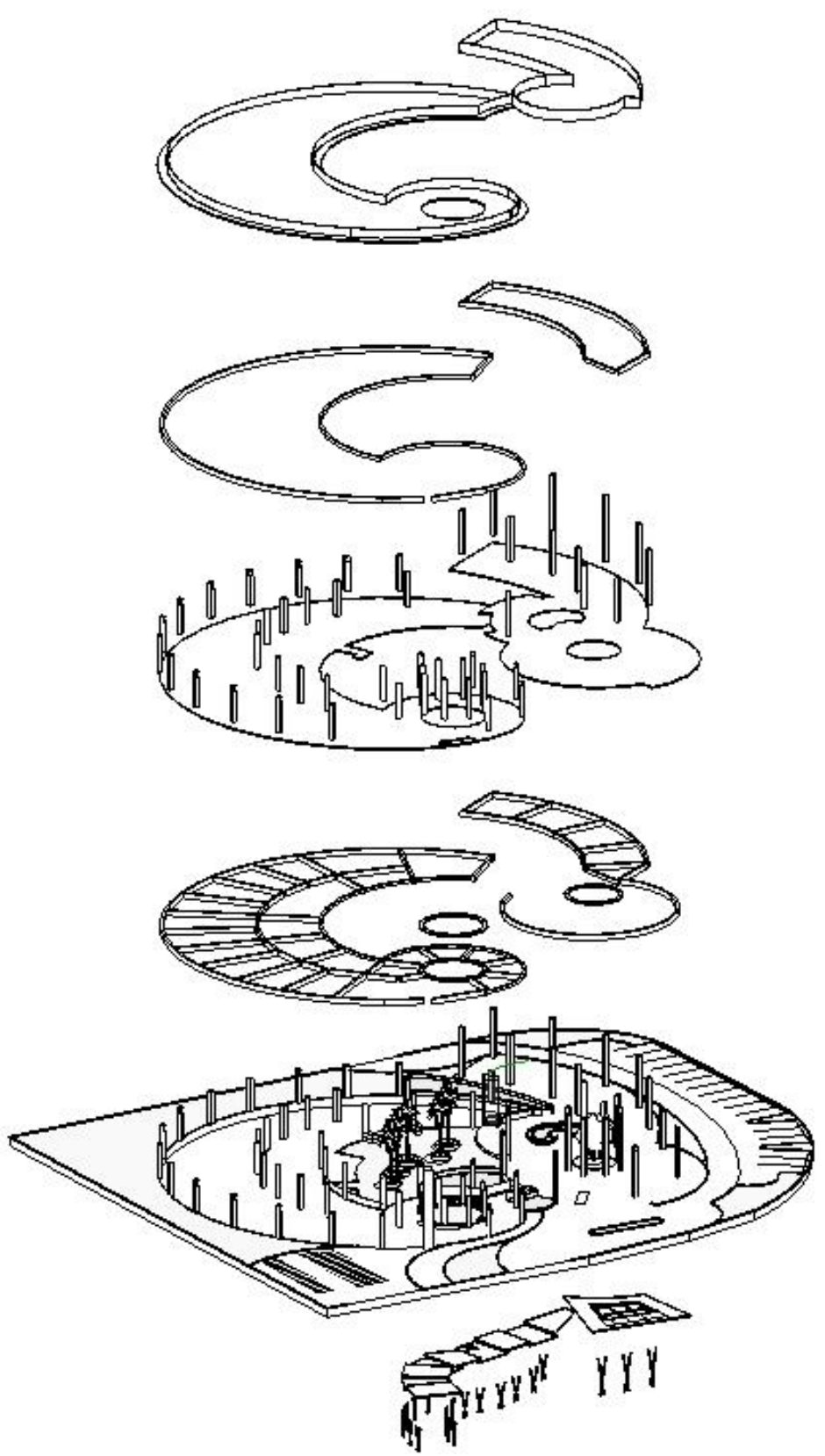

Gambar 10. Exploded Struktur

Struktur yang di gunakan menggunakan struktur radial yang mengikuti bentuk masa bangunan, sehingga bentang kolom maupun balok tidak membuang tempat dalam ruangan, sehingga dapat pengunaan ruang bisa maksimal tanpa terhalang oleh struktur. Sehingga bangunan pusat kreativitas remaja dan anak muda milenial yang memiliki 2 lantai ini seluruh ruangan bisa maksimal dalam pengunaan.

\section{KESIMPULAN DAN SARAN}

Pembangunan proyek bangunan Pusat Kreatifitas Remaja dan Anak Muda Milenial dirasa sangatlah perlu, karena kaum milenial kususnya para remaja dan anak muda sangatlah banyak di negara berkembang seperti Indonesia. Dan juga perlu didirikan, karena bangunan seperti ini sangatlah besar peminatnya, dan juga bisa mengubah cara berfikir kaum milenial. Diharapkan banyak peminatnya baik itu remaja maupun anak muda milenial khususnya yang tinggal di kawasan Alam Sutera, Tangerang karena proyek ini sudah di sesuaikan juga dengan program 
kegiatan yang paling banyak di minati oleh milenial kawasan Alam sutera. Salah satu alasan harus di dirikan proyek ini karena masih minimnya bangunan seperti ini yang bisa melakukan banyak sekali aktifitas dan kegiatan pengembangan bakat kreatifitas sekaligus di satu bangunan secara bersamaan secara komersial dan terstruktur. Sehingga anak muda yang sedang usia sangat produktif bisa terus ber inovasi. Para pengunjung dapat bertemu komunitas yang memiliki kegemaran yang sama sehingga bisa bertukar pikiran serta menambah wawasan, mereka dapat melakukan kegiatan dengan diajar tim pengajar maupun bintang tamu yang berkompeten di bidangnya. Sehingga para pengunjung bisa berasa senang dan semangat menjalani seluruh kegiatan di bangunan ini karena semua sesuai dengan bakat dan minat mereka sendiri. Dan juga mereka tahu semua aktifitas yang mereka lakukan di bangunan ini akan membawakan hasil bagi dirinya, ketika dirinya sudah mengikuti beberapa kegiatan baik itu kegiatan harian / lanjutan di harapkan dapat menjadi bekal untuk mencari penghasilan tambahan dan juga berjiwa wirausaha/ entrepreneur.

\section{REFERENSI}

De Chiara, J., J Crosbie, M. (2001). Time Saver Standards for Building Types.Singapore: McGraw Hill Book Companies Inc.

Echols, J.M. dan Shadily, H. (2005). Kamus Inggris Indonesia : An English - Indonesian Dictionary. PT Gramedia, Jakarta.

Specht, J. (2014). Architectural Tourism. Belanda : Springler Gabler.

https://www.scribd.com/document/349368816/ Standar-Ruang-Kreative-Center

http://ejournal.uajy.ac.id/8768/7/6TA13991.pdf

http://smartbuildingindonesia.blogspot.com/

https://www.kominfo.go.id/content/detail/8566/mengenal-generasi

millennial/0/sorotan_media 